\title{
Membayangkan Tanah Air di Alam: 'Heimat' dalam Relasi Manusia-Hutan di Jerman Selatan
}

\author{
Fahmi Rizki Fahroji \\ Alumni Departemen Antropologi, Universitas Gadjah Mada \\ Email: fahmi.rizki.fahroji@mail.ugm.ac.id
}

\begin{abstract}
What is an appropriate thing to explain the phenomenon of human-forest attachments in this sophisticated space of time, when life seems no longer belongs to the traditional relationship? This article aims to explain the German identity in the discourse of forestry, which appears as a natural phenomenon and as a source of life (spirit) that leads to the narration of homeland. In this study, the empirical data of Heimat wer gathered using ethnographic research methods conducted at the WaldHaus, Freiburg. The study will also look at how the 'homeland' paradigm has been used from generation to generation until this study is conducted in the stories about people and their trees. Through Heimat, discourses and discussions amidst humans and forests are often conceptualized as a culturally rooted reality. Svasek's (2002) Heimat, which is also related to Foucault's (2002) archaeology of knowledge, becomes an essential field in understanding the symptoms of this multispecies interaction from an anthropological perspective. This research is significant because, in terms of cultural characteristics that can be seen in multiple dimensions, such as the relationship between forests and Germans, the cultural ideology of Germany will be completing the previous research that was inclined more literal, political, social, but apolitical, and historical.
\end{abstract}

Keywords: the archaeology of knowledge, Heimat, the German Forest, human-forest attachment, homeland

\begin{abstract}
Abstrak
Hal apa yang cocok untuk menjelaskan fenomena keterikatan manusia dan hutan di ruang waktu yang kompleks ini, ketika kehidupan tampaknya tidak lagi menyentuh hubungan yang tradisional? Tulisan ini hendak menjelaskan identitas Jerman dalam representasi wacana kehutanan yang tidak hanya muncul sebagai gejala alam, melainkan juga sebagai sumber kehidupan (anima) yang bermuara pada narasi tanah air. Dalam penelitian ini, data empiris mengenai heimat dikumpulkan menggunakan metode penelitian etnografi yang dilakukan di Waldhaus, Freiburg. Tulisan ini juga akan melihat secara ringkas seperti apa sejarah penggunaan paradigma ke-'tanah-air'an dari generasi ke generasi hingga penelitian ini berlangsung dalam relasi manusiahutan di Jerman Selatan. Melalui konsep tradisional heimat, diskursus dan narasi pelibatan manusia-hutan banyak diceritakan sebagai realitas kultural yang mengakar dari masa lampau. Heimat yang dipopulerkan Svasek (2002) dikaitkan pula pada
\end{abstract}


arkeologi pengetahuannya Foucault (2002) menjadi arena penting dalam menafsirkan gejala hubungan multispesies ini dalam kacamata antropologis. Studi ini penting dilakukan karena sejauh corak kebudayaan bisa dilihat pada aspek multidimensional, seperti hubungan hutan dan orang Jerman, maka ideologis kultural Jerman Selatan di hutan akan menjadi suatu penyempurnaan dalam kajian-kajian sebelumnya yang lebih berorientasi literal, politis, sosial namun apolitis, dan historis.

Kata Kunci: Arkeologi pengetahuan, heimat, hutan Jerman, kelekatan manusiahutan, tanah air

\section{Pendahuluan}

Tulisan ini berangkat dari perspektif bahwa hutan bukan gejala biologis yang berdiri sendiri, tetapi merupakan ruang hidup kultural orang Jerman Selatan. Dipandang sebagai tempat bermunculnya energi, muara semangat berkegiatan sehari-hari, dan 'jiwa'-nya orang Jerman, pepohonan sebagai satuan kecil dari hutan telah memicu tanggapan simbolis -atau lebih tepatnya ideologis - dari masyarakat, utamanya masyarakat Jerman Selatan (Tange 2018). Hutan sebagai energi dan sumber kehidupan adalah bentuk dari makna dan tafsir atas tindakan-tindakan yang mencuat dalam semangat berkebudayaan bagi orang Freiburg (Fahroji 2020). Tulisan ini akan banyak berbicara mengenai wacana hutan Jerman sebagai "anima" yang metaforik, alih-alih praktik penggunaan hutan di Freiburg. Meskipun studi mengenai hutan Jerman banyak dilihat dari dimensi teknis dan literal, melalui tulisan ini, saya hendak mengikuti jejak studi sejarawan Jerman dan romantik kuno yang lebih melihat hubungan multispesies orang Jerman Selatan sebagai ruang ideologis, sosiokultural, dan politis yang empiris. Pertanyaan penelitian yang hendak dijawab kemudian adalah: bagaimana masyarakat Jerman Selatan, secara luas, membayangkan tanah airnya melalui hutan, pada gagasan, tindakan dan senarai perilakunya di hutan?

Studi ini memadukan narasi sejarah, politik, antropologi lingkungan, dan studi kehutanan. Kurun waktu kerja lapangan dilakukan di kota Freiburg dalam 20 hari penelitian di salah satu yayasan nirlaba, yaitu Stiftung Waldhaus Freiburg. Selama periode tersebut jamak dilakukan obrolan informal dengan pengurus yayasan, pengunjung atau masyarakat awam, mountain bikers, peneliti dan akademisi. Sekali waktu dalam jangka pendek saya mampir ke Kantor Kehutanan Freiburg guna berkenalan dan mendapatkan informasi terkait kebijakan dan sistem kehutanan kota, sembari menghabiskan waktu dengan berjalan mengamati aktivitas-aktivitas yang dilakukan di sekitar wilayah perhutanan Wonnhalde forest area di sisi timur laut kota Freiburg. Di samping karya akademik yang relevan, media cetak dan elektronik Jerman merupakan sumber informasi tambahan dan tak ternilai bagi mendukung fakta-fakta sejarah dan analisis kajian ini. Namun, untuk sebagian besarnya, tulisan ini belum menjangkau Deutscher Wald (hutan Jerman) itu sendiri. Tantangan dan hambatan dalam penelitian kerap terjadi sehingga pilihan studi kasus dilandasi sejumlah faktor, sebagiannya analitis, sebagian lainnya tergantung keadaan.

Alih-alih melihat hutan sebagai ruang sosial-kultural, dalam dua dekade terakhir akademisi dan ahli kehutanan lebih tertarik membahas ekosistem kehutanan 
sebagai era baru tata kelola kehutanan di Jerman (Fahroji 2020). Ihwal pandangan ini mengartikulasikan bahwa pepohonan dilihat sebagai gejala fungsional-fisik, ekologis dan ekonomis. Misal, narasi soal teknik Sylvicultura Oeconomica, rantai pasokan timber (kayu gelondongan), dan penggunaan kayu sebagai furniture abad ke-19 mendominasi diskusi akademisi yang melihat produk hutan adalah benda yang bernilai secara fungsionalekonomis (Thomasius 1994; Warde 2006; Brandl 2006). Hal ini mengindikasikan satu persoalan bahwa paradigma mengenai manajemen hutan di masa lampau masih didasari oleh pikiran untuk tetap bertahan hidup, memperkuat paradigma power and profit (Askins 2014). Untuk narasi-narasi yang tidak tampak, yang sifatnya ideologis, mangkruk begitu saja. Kebanyakan, pembahasan hutan Jerman dalam aspek ideologi-naratif muncul pada karya fiksi hubungan antara hutan Jerman dan sejarah romantik kuno yang meyakini bahwa tuntutan ekologis budaya Jerman muncul dari hutan (Heske dalam Lee et al. 2005). Konstruksi budaya ini diperkuat kembali di era Romantik, tepatnya pada abad ke-19 oleh kaum "Germania".

Oleh sebabnya, terma Deutscher Wald (hutan Jerman) juga merupakan teknologi politis (Agrawal 2005) yang berupaya mengurangi pandangan dominan terdahulu bahwa koneksi orang Jerman Selatan dengan hutan hanya didasarkan pada romantisme agraria, meluputkan kajian terkini mengenai modernisasi (Wilson 2012). Bagaimana pun, dua aspek di atas menjadi penting bagi tulisan ini yang hendak mensintesiskan kenyataan hutan Jerman masa kini yang tidak bisa dihalau oleh pengalaman masa lalu. Secara umum, narasi-narasi tersebut berikatan langsung dalam kisah kecintaan masyarakat dan hutan di Jerman Selatan yang tak bisa lepas dari campur tangan manusia. Perhatian saya pada studi-studi yang pernah dilakukan sebelumnya akhirnya berfokus terhadap penerjemahan relasi manusia-hutan, yang di dalamnya muncul makna, alasan dan persepsi terhadap lingkungan-hingga konstruksi yang terbentuk pada hari ini, yang melambangkan hutan Jerman sebagai identitas nasional.

\section{Kerangka Konseptual: Heimat dan Arkeologi Pengetahuan}

Keterkaitan antara hutan Jerman dan realitas sosial itu lantas hendak diuji dengan konsep "archeology of knowledge" (Foucault 2002), di mana arsip-arsip pengetahuan bukanlah serangkaian hal (a set of things) atau serangkaian pernyataan (a set of statements), melainkan serangkaian hubungan (a set of relation). Secara empirik dalam konteks heimat, serangkaian hubungan itu tertulis pada jejak hubungan manusia dengan hutannya, mulai dari adanya praktik tradisional dan kecintaan terhadap lingkungan di abad ke-18 hingga kini. Jejak itu berkaitan dengan nilai-nilai kebudayaan Jerman yang di kontestasikan, dinegosiasikan, dan dikompromikan pada relasi manusia-hutan di Freiburg yang ditemukan dalam wacana keseharian, sebagaimana riset ini dipadupadankan. Ringkas kata, temuan saya mengatakan bahwa serangkaian hubungan orang Jerman di Freiburg telah memungkinkan adanya pemaknaan kembali konsep tradisional heimat_perasaan tanah air-pada kelompokkelompok yang memiliki keterikatan terhadap hutan.

Bagi saya, orang Freiburg (Jerman Selatan) bisa saja tidak mengakui konsep heimat

$1 \quad$ Konstruksi hutan Jerman masa itu banyak sekali dipengaruhi budaya populer yang kemudian dikaji secara ilmiah oleh para pakar studi Jerman, antropolog dan sejarawan ternama Jakob Grimm (Birkenstock 2014). 
sebagaimana para sarjana awal abad ke-19 melihat gagasan ini sebagai sesuatu yang antagonistik: sangat biadab, bengis, dan horror. Namun kiranya perlu digaris bawahi juga, kalau buah pemikiran dan aktivitas keseharian yang subjektif pada orang Jerman hari ini merupakan produk kehidupan yang kronologis dan diakronis; terlepas dari konsep heimat ini selanjutnya dimanipulasi oleh Nazi atau diromantisir oleh penyair, bangsawan, dan budayawan pada medio abad ke-19 dan 20 (Wilson 2012; Lekan 2004). Dengan kata lain, gagasan tentang tanah air dalam tulisan ini adalah kajian yang kritis dan politis. Disposisi individu dalam pengaruh struktur dan kuasa pengetahuan (power of knowledge) tertentu menjadikan kisah kehidupan orang-orang, persepsi tentang kampung halaman pada akhirnya bergantung pada pengalaman, norma, tujuan, dan evaluasi pribadi dan kolektif orang-orang. Sebagaimana ditunjukkan oleh Svasek:

"If 'home' is the story of people's lives, the perception of home is ultimately dependent on people's personal and collective experience, norms, goals, and evaluations. Evidently, individual people's perceptions and dispositions are also influenced by changing structural possibilities and limitations, and by their involvement in social and cultural practices of (re-) embedding" (Svasek 2002, 514).

Heimat adalah suatu konsep yang lekat dengan persepsi terhadap tempat (place), kelekatan terhadap tempat (place attachment) dan perasaan akan tempat (sense of place). "Kelekatan" yang saya maksud pada bagian ini sangat cocok untuk dijadikan sebuah kata kunci karena selain sifatnya yang cukup personal, kelekatan juga merupakan sesuatu yang menubuh (embodied) dan memperangai (embedded). Ratter dan Gee pun menyepakati pandangan ini bahwa heimat merupakan "... a useful framework for exploring what people consider to be special about their living environment and what aspects they particularly value and feel attached to" $(2012,136)$. Seperti sebuah ungkapan, di mana bumi dipijak di situ langit dijunjung, lingkungan sosial yang mengidentifikasi orang Jerman pada ciri tertentu ini benarlah sebuah hal yang lekat. Apalagi pelekat diri itu sudah menjadi aturan sosial, norma, perilaku sehari-hari, dan dimaknai pada serangkaian hubungan yang jauh lebih kompleks seperti memori hutan masa lalu, kesadaran akan lingkungan, dan keinginan untuk hidup harmonis dengan pepohonan.

\section{Narasi Diakronis Heimat dalam Konteks Kehutanan}

Secara diakronis, terdapat kecenderungan umum dalam pola hubungan masyarakat Jerman Selatan dengan hutannya, yang dinamis dan juga mengalami perubahan sosio-ekologis sebagai hasil dari perubahan sosial-politik yang fenomenal. Dalam sejarah Jerman sendiri, hutan-yang dimaknai sebagai tanah dan kekayaan alam-telah mengalami ragam proses penguasaan dan eksploitasi dalam kurun waktu ribuan tahun. Namun, pada konteks tulisan ini di mana wacana "hutan adalah sumber kekayaan dan kekuasaan" tampaknya telah menyimpan nilai "kecintaan pada hutan sebanding dengan tanah air", tentu seiring dengan perubahan laku sosial yang terjadi. Kendati demikian, sepakat dengan Wilson (2012), implikasi dialog terkait hutan dan heimat selain mempersatukan identitas Jerman, juga dapat berfungsi bagaikan kendaraan untuk mobilisasi dinamika berkehidupan sehari-hari.

Studi tentang heimat telah banyak dilakukan oleh para akademisi baik pada bidang politik, antropologi, kajian Jerman dan Eropa, geografi, human geography maupun ilmu 
sejarah (lihat Lekan et al. 2005; Lee et al. 2005; Lekan 2004; Wilson 2012; Ratter dan Gee 2012; Svasek 2002; Jäger 2018). Mengacu beberapa literatur tersebut, heimat memiliki makna yang jamak, tergantung bagaimana para ahli mengartikannya. Sejauh penelusuran saya, konsep heimat acapkali diandaikan sebagai konsep kelekatan pada tanah air; fatherland/homeland. Dengan kata lain, relasi manusia - hutan, sebagai part of nature dan konstruksi "ke-tanah air-an" orang Jerman Selatan, adalah wilayah yang mestinya dapat diidentifikasi secara ilmiah. Apalagi, intervensi relasi manusia di dalam menciptakan dan memaknai lingkungan kerap berimplikasi kepada pertanyaan terbuka tentang masa lalu (sebuah jejak historis suatu bangsa) bahwa: Bagaimana konstruksi masyarakat Jerman Selatan terhadap hutan-hutan yang mereka ciptakan? Seperti apa sejarah hutan berkaitan dengan realita kehidupan masyarakat dari waktu ke waktu?

Singkatnya, sejarah lingkungan sebagian besar adalah sejarah manusia (Radkau 1996; Wilson 2012). Hutan, tak ayal adalah produk kebudayaan hasil dari perkawinan antara alam dan kultur suatu bangsa, disebut Marvin Harris (dalam Moore 2012) sebagai budaya material. Laiknya budaya material, hutan sendiri terdiri atas aspek-aspek kebudayaan (Ahimsa-Putra 2013) yang terdiri dari, antara lain: aspek material melingkupi pohonpohon monokultur yang dibangun di atas tanah, aspek perilaku yang melingkupi tindaktanduk dan cara-cara merawat serta mengatur hutan, aspek bahasa yang mencermati istilah, wacana, bahasa sehari-hari (vernacular) yang menempel pada komunitas nasional di rentang waktu tertentu, dan pengetahuan serta nilai-nilai yang terjaga, baik pada satu generasi dan ruang tertentu atau bahkan di lain generasi.

Dalam konteks tulisan ini, lanskap (hutan) memainkan peran penting dalam membentuk imajinasi bangsa (Smith 1986). Secara empiris, kisah pelambangan (signing) pohon Ek $(\mathrm{Oak})^{2}$ sebagai lambang nasional pada era Sosialis Wilhelm 1 pada tahun 1871 tidak hanya menyiratkan pohon sebagai simbol politik dan kekuasaan, juga membentuk wacana berlanjut yang diekspresikan pada sederet tindakan. Saat itu, Ek digadang-gadang sebagai simbol kesetiaan, patriotisme, dan maskulin dalam kekuatannya, dan di beberapa momen ia dikaitkan pada narasi soal Vaterland - tanah air bapak bumi. Masa lalu dan lanskap nasional yang dikonstruksi ini, sering kali saling terkait, dan akhirnya membentuk elemen sentral identitas nasional (Fahroji 2020). Sebagai entitas yang jamak, konteks perhutanan yang monokultur (satu jenis, yaitu pohon Ek) akhirnya menjadi lambang (sign) kebangsaan.

Catatan sejarah melihat setidaknya penetapan Ek sebagai lambang nasional itu telah berhasil diapropriasi pada media-media seperti lirik lagu, poster, dan majalah serta sisipan gambar pada buku-buku cetakan (Wilson 2012, 206). Di lagu, lirik-lirik semacam "Deutschland, Deutschland über alles!" (Jerman, Jerman di atas segalanya!) lebih sering dipublikasikan. Ek yang sama pula digunakan untuk menyatukan bangsa secara simbolis di sampul buku bergambar milik Joseph Kurschner pada tahun 1896 dengan judul yang kontroversial saat itu, yaitu "Das ist des Deutschen Vaterland" (Ini adalah Tanah Jerman). Dua contoh ini menyiratkan suatu makna, bahwa jiwa patriot dan nasionalis Jerman

2 Cerita ini pertama kali diberitakan di majalah Illustrierte Zeitung sebagai "The German Oak" pada 17 Juni 1871 dengan tajuk 'Die deutsche Eiche: Ehrengabe für Seine Majestät den Deutschen Kaiser' [Ek Jerman: Hadiah kehormatan untuk Yang Mulia Kaisar Jerman] (Wilson 2012, 203). 
telah mengakar bukan hanya sebagai lambang, tetapi juga kebudayaan nasional yang ajeg dan baku di abad ke-19. Meminjam istilah Cassirer (1945), simbol ini mencirikan secara sadar kalau masyarakat Jerman Selatan adalah animal symbolicum, individu yang mampu memberikan pelambangan (simbolisasi) terhadap suatu hal yang menjadi dasar pijakan mereka bertindak. Teori-teori kebangsaan, seperti imagined communities-nya Anderson (1991), juga mengakui bahwa terdapat cetak biru (print capitalism) identitas pada satuan kolektif warga untuk ditampilkan. Artinya, cetak biru itu bisa kita lihat dalam simbolisasi hutan Jerman sebagai identitas nasional.

Alih-alih menandai simbol nasional, temuan mengejutkan terkait sejarah pemaknaan hutan pun tampak digaungkan pada cerita-cerita rakyat (folklore). Adalah kisah-kisah romantik abad ke-19 dan 20 yang diabadikan oleh pengarang dan penyair saat itu yang mengindikasikan peran simbolis hutan-dan sekali waktu juga untuk menunjukkan rasa primordialisme, kebanggaan pada Jerman. Misal, pada kisah petualangan Hansel und Gretel yang dibuat 'The Grimm Brothers' pada abad ke-19 menceritakan romantisme hutan dengan kisah yang hampir serupa, seperti Little Red Riding Hood ${ }^{3}$. Serta masih banyak lagi cerita tentang kehidupan yang berkesan romantis seperti karya operanya Wagner Siegfried yang melantunkan musik kemilau hijau hutan Jerman yang dimaknai sebagai "German Banner":

Who has built you, you beautiful forest,

Up there, so high above?

I truly want to praise your Master,

As long as my voice shall sound.

Farewell,

Farewell, you beautiful forest! (Borchmeyer 2019)4

Sekilas kita melihat kalau hutan Jerman sendiri pun tidak lepas dari narasi romantik yang seolah-olah menciptakan kesan bahwa masyarakat Jerman memang begitu erat dengan pepohonan yang hidup di sekitar mereka. Saya sepakat dengan Linke $(1990,126)$, kisah kecintaan pada cerita rakyat itu hanya untuk legitimasi government of social life, upaya untuk menciptakan "sistem" perilaku dan identitas individu sehari-hari di bawah kendali nilai sosial. Nilai-nilai di mana romantisme terhadap alam adalah upaya untuk menjadi bagian integral kehidupan multispesies. Namun, narasi ini justru mesti dikritik kembali, sebagaimana dijelaskan di bagian-bagian awal tulisan ini, bahwa koneksi orang Jerman dengan hutan tidak melulu hanya didasarkan pada romantisme agraria, tetapi juga kondisi modernisasi dan kekuasaan yang hidup saat itu (Wilson 2012).

Kendati demikian, sejarah hubungan harmonis manusia dan lingkungannya itu sendiri acapkali menjadi senjata politik yang dimanipulasi oleh Hitler pada abad ke-20,

3 Tautan ini merupakan karya Grimm Brothers lainnya yang menjelaskan alegori politik Hitler dengan Nazi-nya yang menyeret narasi diakronis Jerman pada cerita rakyat. Yang menjadi sorotan dalam konteks tulisan ini adalah cerita bagaimana seorang anak perempuan berkostum Swastika diselamatkan oleh seorang Führer, Adolf Hitler, dari ancaman serigala besar di hutan.

4 Diterjemahkan oleh Nora Krug, musik ini mengisahkan tentang kecintaan Jerman di masa romatik terhadap hutannya yang diakui menjaga dan senantiasa menginginkan agar Tuhan merawatnya. 
untuk melanggengkan pandangan nasionalis yang cenderung 'kanan' (right wings), rasis dan patriarkal (Fahroji 2020). Ideologi "Blut und Boden" (Darah dan Tanah) menjadi narasi tak tergantikan sepanjang Hitler menguasai rezim, dan tak ayal bahwa hutan telah bergeser maknanya sebagai 'boden' (lahan) yang harus dirawat, diatur, dan dimoderasi untuk kepentingan politis. Citra hutan ini lah yang dimonopoli saat Nazi berkuasa sebab mampu menciptakan power and profit. Nazi dalam hal ini menggeser lokalisme heimat menjadi ideologi nasionalis (Reich) (Wilson, 2012: 217). Bagaimanapun, keterkaitan ideologi fasis dengan orang Jerman saat itu bukanlah acuan tunggal yang mempengaruhi kultur kecintaan masyarakat akan lingkungannya, melainkan meliputi pengetahuan, nilai, dan spirit orang Jerman merawat lingkungannya.

\section{Mengurai Kelekatan Masyarakat dan Hutan: Cerita dari Lapangan}

Mengurai adalah memilah-milah. Nalar dan relasi kultural masyarakat Freiburg dan hutan hari ini tidaklah lahir dari ruang ideologi yang kosong. Relasi itu merupakan produk yang dibesarkan oleh jejak sejarah yang rumit dan kontestatif. Namun pada satu titik, perlu diuraikan kalau orang Freiburg hari ini memiliki laku tertentu dalam merawat dan menghargai lingkungan. Judul "Kelekatan" menguraikan bagaimana identitas dibentuk secara relasional, seiring dengan berkembangnya kebiasaan 'menyehari' (habitus) serta struktur perasaan tertentu di antara relasi masyarakat Jerman dengan hutannya yang resiprokal. Elemen-elemen material, sosial, politik, dan sejarah dalam bagian ini akan menguraikan tiga poin inti mengapa relasi manusia-hutan di Jerman Selatan selain dapat melambangkan simbol nasional, juga diartikulasikan pada kehidupan 'menyehari' orang Freiburg dan Jerman secara umum. Uraian itu setidaknya, namun tidak terbatas, akan menyisir pada, pertama, nilai-nilai tradisional heimat yang masih diekspresikan dalam praktik penggunaan hutan di Waldhaus; kedua, hutan sebagai produk estetika alam (Cronjäger 2021) yang diproyeksikan melalui pajangan visual, seperti poster, perangko, dan kartu pos serta kriya tulis yang dibahasakan; terakhir, nalar dan pikiran orang Freiburg tentang hutan Jerman kaitannya pada kecintaan terhadap tanah air.

\section{Waldhaus Freiburg: Mengapa Hutan Dirumahkan di Freiburg?}

Mencintai Jerman dan tanah airnya barangkali tidak memaksakan setiap individu untuk terkoneksi secara keseluruhan pada apa yang dimiliki negaranya, melainkan bisa dengan contoh kecil pada apa yang dimiliki oleh wilayahnya. Itu lah yang saya tangkap dari sepasang suami istri paruh baya usai obrolan kami di Waldhaus. Mereka mengatakan migrasinya ke Freiburg tidak mengurungkan kecintaan dan kelekatannya pada Jerman melalui hutan yang diingatnya semasa kecil.

"For me, forest means regeneration and adventure. You just feel good about it. Freiburg is a little city. But I lived before only in bigger cities like Berlin and Frankfurt and there, the green and the forest, are missing. I grew up in the countryside where there is always a forest and I have known that since I was a child. For me, the forest was something natural 
here..." (wawancara, 19 Mei 2019). ${ }^{5}$

Cerita tentang sepasang suami istri itu barangkali menjadi regenerasi baru bagi mereka yang hengkang dari kota besar ke kota kecil, namun tetap mendasari hutan adalah bagian dari kelekatannya. Namun perlu diingat lagi bahwa konstruksi ini muncul tak lain juga mendasari konteks praktik penggunaan hutan secara lebih luas-yang mendasari kelekatannya dengan "kewilayahan" (Greverus dalam Jens Jäger 2018).

"Kewilayahan" (territoriality) dalam konteks heimat mengartikulasikan Jerman Selatan dengan produk lokalitasnya yang menjulang di tiap daerahnya, seperti Freiburg dan hutannya. Konsep kewilayahan yang saya gunakan, sebagai turunan dari teori dasar heimat, mengartikan spesifitas materi kebudayaan yang dirujuk, yaitu area kehutanan Waldhaus. Merujuk Greverus (2018), seorang antropogeografi, territoriality memiliki peranan penting dalam mendeterminasi koneksi antara individu dan tempat yang memenuhi kebutuhannya untuk menyediakan behavioural security (keamanan berperilaku). Kalau kita barangkali mengenal istilah "jago kandang" sebagai konotasi yang mendiskreditkan, dalam 'kewilayahan' unsur serupa hadir dalam makna yang sedikit berbeda: individu mampu mengetahui, mengartikan, dan mengartikulasikan tindakannya karena lebih mengenal wilayahnya ketimbang orang di luar daerahnya.

Agar pemahaman ini lebih mudah dipahami, temuan di lapangan mengindikasikan ekspresi dari konsep di atas. Contohnya, pada abad ke-19 dan 20, di wilayah Rheinebene atau Dataran Rhine Atas telah terjadi realokasi dan pemekaran lahan tutupan hijau menjadi wilayah pemukiman. Para ilmuwan bercerita bahwa wilayah Sungai Rhine Atas ini sebagai jalan perniagaan dan pengiriman timber pada abad ke-19 dan 20. Oleh David Blackbourn (2013) pada "The Culture and Politics of Energy in Germany: A Historical Perspective", daerah ini merupakan akses perdagangan timber yang biasanya dikirimkan ke Amsterdam, Belanda. Berkat pengetahuan wilayah dan lingkungannya, koneksi masyarakat dengan hutan saat itu terbatas pada kepentingan ekonomi. Akibatnya, kerusakan hutan yang tak terbayangkan dan tegakan kayu yang terus berkurang menambah salah satu masalah paling mendesak yang dihadapi oleh kota itu pada awal abad ke-19.

Pada saat itu, kerusakan hutan di Eropa juga menjadi perhatian khusus pemerhati hutan dan lingkungan di dunia (Askins 2014). Namun yang paling menarik dari jalan penanaman itu tak lain adalah "pemulihan dosa" Freiburg pada wilayah hutan yang dieksploitasi untuk pemekaran kota dan kayu-kayunya yang dijual ke beberapa negara bagian Jerman, seperti Hamburg (Fahroji 2020).

Sebagai upaya pemulihan dosa, hubungan masyarakat dan hutan pun bertransformasi kepada dogma dan kepentingan yang lebih ekologis. Istilah back to nature lantas mencuat sebagai pompa bagi peningkatan kesadaran lingkungan di Freiburg yang lantas narasi mengenai ini berkaitan pada pembentukan keamanan berperilaku (behavioral security) warga Freiburg di wilayah kehutanan dan yayasan Waldhaus. Menurut Rossmässler (dalam Imort 2005) back to nature dulu dipakai dalam istilah konservatisme secara umum agar hutan dapat dimanifestasikan secara sosial. Tentu, Waldhaus sebagai penata layanan

5 Beberapa orang yang diwawancarai sengaja tidak saya tampilkan namanya di sini untuk kepentingan privasi. Adapun hasil wawancara sudah melalui tahapan translasi antar mitra peneliti dengan korespondensi berlanjut melalui email. 


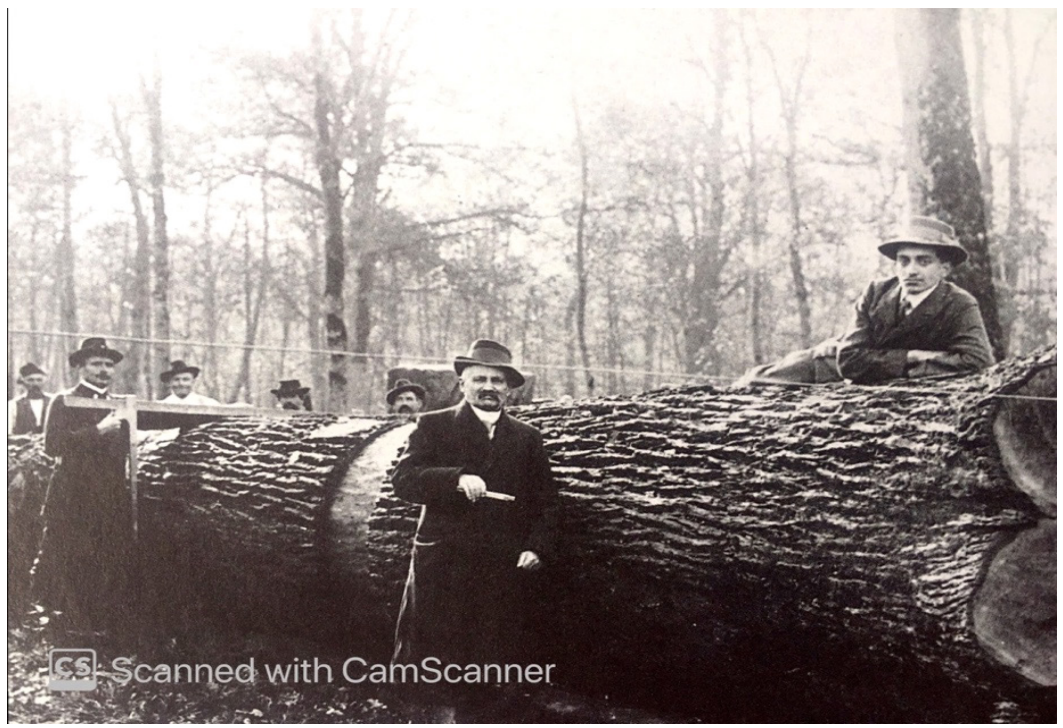

Gambar 1. Musim dingin, 1912/1913: rimbawan tengah berpose dengan tebangan pohon Ek (Oak) di hutan belukar Mooswald untuk dijual ke UIm (salah satu kota di negara bagian Baden-Württemberg, Jerman selatan dan pelabuhan kapal di Hamburg untuk dijadikan galangan kapal (sumber: disadur dari dokumentasi milik Martha Müller dalam buletin terbitan Forest Perspectives 2000)

juga memproses dan mendistribusikan kebijakan dan aturan penggunaan hutan secara organisatoris dengan menakar dua fungsi utama, yaitu sosial dan ekologis. Laksana rumah, Waldhaus akhirnya mampu menciptakan dinamika pada pembentukan aktivitas fisik dan manfaat emosional.

\section{Hutan, Estetika Alam: Proyeksi Tanah Air di Selembaran Poster}

Hutan-hutan yang diwacanakan di Jerman juga berkelindan dengan sejarah panjang rekonstruksi pandangan manusia terhadap alam dan tanah airnya yang sifatnya sangat sehari-hari (Wilson 2021). Rekonstruksinya itu tak jarang diwujudkan pada seni, musik, puisi, poster dan media surat (postcard, gambar dan perangko). Misal, pada tahun 1952, Gerth dan Oppenrieder mencetak poster pameran Kulturbund oleh seniman Lienert dan Schirner yang bertajuk "Nature and Homeland". Poster itu, menurut Jens Jäger (2018), seolah menceritakan gambaran heimat ideal dari segi geografis, lingkungan sosial dan konteks wilayah tanpa intervensi modernitas waktu itu.

Pemandangan kota dengan gereja di tengah tertanam dalam lanskap yang menggambarkan hutan, ladang, bukit, dan air. Gambarnya berwarna, menggaris bawahi gagasan kontemporer tentang karakter estetika dan alami dari pemandangan itu. Adegan seperti itu umum pada kartu pos seantero Jerman (Jäger 2018, 6). Seolah menyiratkan imajinasi Jerman dalam satu gambaran, seakan mendoktrin para pelihatnya bahwa alam dan Jerman merupakan satu kesatuan, dan itu situasi ideal yang kian diekspektasikan.

Sama halnya dengan Freiburg, fakta mengenai postcard dan gambar di dalamnya

6 Di posternya berisi keterangan, "Sebuah desa kecil di tengah lanskap pertanian yang sedikit berbukit, dengan pertanian skala kecil. Burung hantu dan pohon pinus menunjukkan hutan. Tidak ada ruang untuk modernitas dalam gambar ini - bahkan pada tahun 1952 model ikonografi gerakan Heimatschutz dari era kekaisaran dilibatkan dalam GDR”(Jäger 2018). 


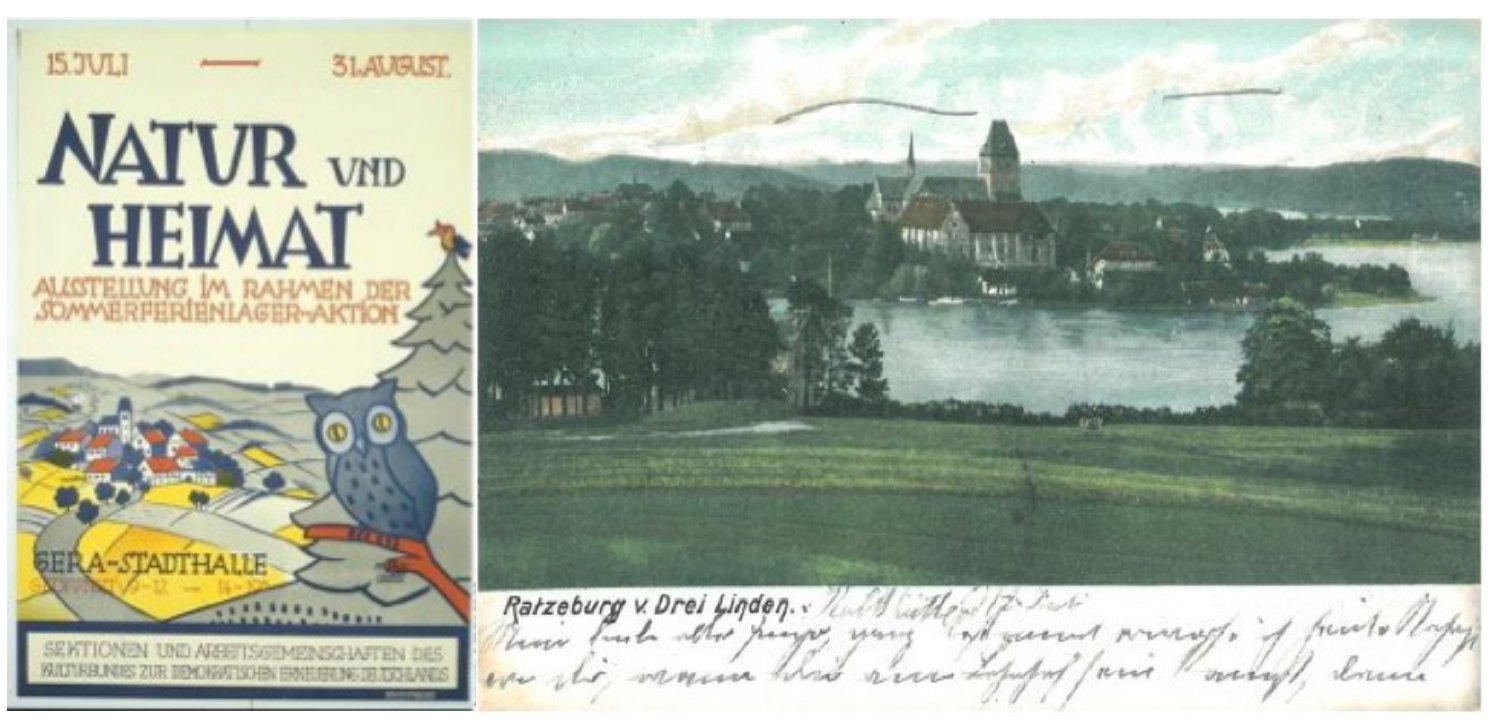

Gambar 2. (Kiri) Poster Pameran "Nature and Homeland" 1952 dan (Kanan) Postcard "Ratzeburg v. Drei Linden” (sumber: Bundesarchiv B 285 dalam Jens Jäger 2018)

menyebar pada toko-toko souvenir, oleh-oleh dan pusat perbelanjaan di pusat kota ${ }^{7}$. Ibarat seorang turis, melihat postcard unik nan khas Freiburg berikut terasa seperti membawa Jerman dalam satu lembar kertas lengkap dengan isian pesan yang ingin disampaikan. Begitu pun dengan saya, memiliki postcard bagaikan memiliki memori dan kesan tentang Jerman: seperti dapat menyampaikan pesan kepada yang menerima kartu. Gambar di bawah ini kiranya menyiratkan nuansa kehidupan saat itu, 1905/1906, yang selalu dilatarbelakangi kota di tengah dengan hutan sebagai seting tempatnya.

Di Jerman sendiri, media tukar-menukar pesan tidak hanya terjadi melalui kartu pos, poster dan lagu, tetapi juga dengan film dan puisi. Di film, salah satunya adalah Ewiger Wald (lihat bagian Heimat dalam Konteks Perhutanan), juga pada film-film dokumenter yang banyak membicarakan restorasi dan rehabilitasi hutan di abad ke-198. Begitu pun dalam puisi Lost Heimat, Josef Goss pada Heimatbuch of Brand tahun 1958 ia mengingat tanah air tercintanya dan mengungkapkannya dalam syair:

In a dream, I often see

my Heimat village,

with the lime tree,

looking down from the hills.

I see the Heimat

7 Di Freiburg, pusat perbelanjaan umumnya memusat di tengah kota, di pusat keramaian. Beberapa toko yang menyediakan postcard berdasarkan observasi antara lain: ThaliaBuchhandlung Herder di Kaiser-Joseph-Straße, Münstermarkt dan toko-toko di sepanjang jalan Berthold Strasse serta mini market (REWE, ALDI SÜD).

8 Film-film mengenai hutan Jerman mulai dari dokumenter, siaran pers dan berita sehari-hari tentang hutan banyak direproduksi oleh akun Youtube layanan penyiaran public Jerman, SWR (Südwestrundfunk) atau "Southwest Broadcasting", dapat diakses melalui https://www. youtube.com/user/SWR. 


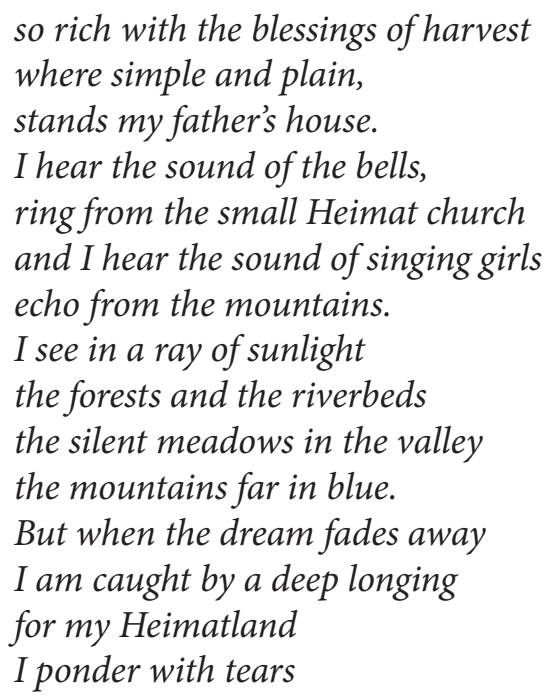

(Goss 1979 dalam Svasek 2002, 503-504).

Konteks cerita pada media tersebut memiliki tipe pesannya masing-masing. Oleh karena dengan media, konteks pada sesuatu dapat dijelaskan secara cermat, dan budaya itu sendiri acapkali memediasi rutinitas sehari-hari orang Jerman dengan makna identitas kultural nya (Svasek 2002, 498).

Dengan demikian, media pesan pada poster, kartu pos dan lainnya merupakan representasi kaitannya pada heimat dan hutan Jerman. Keterkaitan itu tentu tak hanya bersifat tekstual saja, tetapi kontekstual terhadap budaya Jerman. Postcard hanya lah salah satu contoh dari bentuk komunikasi sehari-hari, tidak dibuat dan dijual untuk turis saja, tetapi juga populer di kalangan penduduk setempat. Barangkali dari sederet media tersebut, nilai nostalgia dan emosionalitas kewilayahan menjadi senjata heimat itu muncul dan menyeruak pada banyak aspek. Oleh karenanya, "kelekatan" di sini diartikan bukan hanya bagaimana konteks Jerman dan identitas kebangsaannya padu, melainkan juga pada teks-teks budaya yang sifatnya sehari-hari dan mewasiatkan makna hutan. Namun, mengapa hutan senantiasa dimaknai sebagai "kelekatan" pada kehidupan sehari-hari serta bagaimanakah penafsirannya itu muncul secara individual?

\section{Bernalar di antara Pepohonan: Kisah dari Dua Informan}

Life in the forest

It's throbbing, twittering, rustling and swarming

On the branches and tree trunks, between airy treetops or on the damp forest floor

Life is astir, all over the forest.

Even on the ground, there's plenty going on.

Who's brave enough to explore the dark kingdom of the roots?

(syair dalam bingkai foto di bagian 'hutan' di Museum Natur und Mensch, Freiburg.

Catatan Lapangan, 24 Mei 2019).

“Siapa yang cukup berani untuk menjelajahi kerajaan gelap akarnya (hutan)?” 
merupakan suatu kalimat tameng hutan kepada manusia seakan kegelapan, ketakutan dan kekelaman laksana jiwa yang tumbuh di pikiran. Dahulu, pikiran ini berkembang pada mistifikasi hutan oleh segelintir kelompok kerajaan agar manusia tanpa privilege tidak mengakses hutan seenaknya. Hukum hutan (forest law) semacam ini diakui ampuh dalam menciptakan hutan yang unhumanized nature (Manwood dalam Harrison 1992, 70) hingga fakta itu dibalik saat ini.

Agaknya, cuplikan tersebut seolah menggambarkan oposisi pandangan hutan yang terjadi saat ini, utamanya pada hasil observasi dan dialog saya di Freiburg. Hutan seakan menciptakan kecerahan, kehidupan, kebebasan dan laksana rumah di sebagian orang. Menurut Raumolin (dalam Radkau 1996), kecintaan terhadap hutan adalah ciri khas masyarakat Jerman Selatan. Bahkan, seorang pria bernama Fried dari Rwanda mengaku heran mengapa orang Jerman Selatan begitu cinta dengan hutannya, padahal hanya untuk sekedar bertemu teman dan menghibur diri (lihat DW Euromaxx 2020).

Stephanie Bethmann, seorang praktisi sekaligus pencinta lingkungan, menggambarkan manfaat fisik dan emosional yang dapat ia refleksikan dari kegemarannya mendaki gunung setelah bergabung sebagai peneliti di Forstliche Versuchs- und Forschungsanstalt (FVA) Baden-Württemberg. Beberapa temuan dan pengamatannya dalam riset mengenai hutan sebagai tempat relaksasi dan bagaimana masyarakat awam memanfaatkannya untuk rekreasi telah secara reguler ia lakukan dan hal tersebut berpengaruh dalam membentuk sudut pandangnya. Dalam setiap risetnya, ia selalu memfokuskan aspek inderawi-nya supaya bekerja secara lebih sensitif terhadap objek di sekitarnya dan mengamati bagaimana orang bertindak di hutan (misalnya mencium, menyentuh pohon, menjadi tenang). Oleh karenanya, dari pengalaman pribadi Bethmann serta sedikit pengkajiannya mengenai studi ini, ia beranggapan bahwa kegiatan masyarakat Freiburg di hutan dapat menciptakan energi baru pada manusia, utamanya dalam menciptakan ketenangan (tranquility), sarana kontemplasi dan perasaan liminalitas.

"...it also reveals now a trend that connects forest and health: rationalizing why the forest is good; why forest and trees energize people. There is a research paper about the recreational aspects, the question is: why do people choose forests for recreation? The answers are: when going into the forest it means to physically enter another space, like crossing a border shown by the beginning of trees (people start to relax). And, going to the forest often in combination with rituals and practices, e.g. turning off the mobile phone, being silent, standing in silence, haptic feelings like touching a tree, take the mind away." (dalam kurung penambahan dari saya; wawancara, tanggal 27 Mei 2019).

Pikiran yang secara psikologis berubah itu meyakini bahwa liminalitas pada aktivitas enter another space barangkali laiknya seseorang termenung sejenak di pintu sebelum akhirnya masuk ke rumah. Relaksasi dan menghirup kesegaran (freshness) bagaikan kondisi di dalam rumah yang diidamkan. Dugaan lain juga muncul tatkala hutan dianggap sebagai "embodiment of nature" (perwujudan alam). Di mana sifat alamiah hutan dirasa seperti kebebasan yang didapat setelah pergi dari tekanan keseharian yang kontras di kota, misalnya. Seorang lelaki paruh baya usai program Sonntagspaziergang: Bäume bestimmen menyatakan bahwa:

"I think for me forest is the embodiment of nature. I don't go into the forest because of 
ecological matters. Not in the first place. But because it's a contrast to the city and daily routine. And then you feel personally good." (Wawancara, tanggal 19 Mei 2019)

Di saat bersamaan juga, pasangannya berpandangan serupa,

"I like to go into the woods because it's calming. And the green is a pleasant color that makes me feel good. But I don't go into the woods because of ecological reasons." (Wawancara, tanggal 19 Mei 2019)

Perasaan-perasaan emosional nan subjektif ini barangkali ingin menampakkan citra hutan yang accessible bagi semua orang. Terkait pandangannya seperti apa, itu adalah keputusan setiap individu. Akan tetapi, dari sini saya menemukan pola identitas Jerman (meskipun dilihat secara parsial) yakni, tiap aktor yang beralasan subjektif ditandai sebagai 'jaringan' yang menakar identitas Jerman pada satu ruang kehidupan, seperti hutan. Dalam teorisasi heimat, konsep ini mengacu pada perasaan sense of belonging yang dialami oleh individu ".. as a web of relationships in a specific space that is experienced subjectively" (Wilhelm Brepohl dalam Jäger 2018, 10). Serta akibatnya, imaji kebebasan yang tumbuh, ruang ketenangan dan perasaan akan rumah itu menjadi suatu perasaan dan tindakan yang aman dalam berperilaku (behavioural security). Dengan kata lain, keamanan berperilaku ini menghasilkan ruang sosial budaya sebagai-apa yang disebut-space of satisfaction (ruang kepuasan/pemenuhan), yang mana individu mengalami keamanan subjektif-emosional, identitas dan kebebasan untuk bertindak (Jäger 2018, 5).

\section{Hutan, Jiwa Jerman? Diskusi dan Catatan Kritis atas Heimat}

"Der wald ist die Deutsche seele." [Hutan adalah jiwanya orang Jerman]

-(Martine, warga Freiburg; wawancara, tanggal 19 Mei 2019)

Jika "rumah" adalah kisah hidup orang bernaung, persepsi tentang rumah pada akhirnya bergantung pada pengalaman, nilai, dan momen personal orang tersebut. Namun secara nyata, persepsi individu itu juga rentan berubah seiring dengan perubahan pada struktur yang ada (Svasek 2002, 514), seperti kemunculan keterlibatan masyarakat Freiburg di hutan yang membentuk ruang sosiokultural atas respon terhadap narasi panjang masa lalu. Dalam hal ini, Waldhaus erat kaitannya dalam menanamkan kembali (re-embedding) makna rumah dalam hutan kepada publik. Ruang fisik hutan yang dijajakan tidak hanya sebatas biofisik. Ia juga dikonstitusikan pada bermacam memori dan pengalaman-yang mana hubungannya sering bersifat pribadi dan/atau terkait dengan suatu koneksi (Cheng et al. dalam O'Brien 2005).

Rasanya masih kentara betul dan sangat jelas ungkapan Martine Schiller, pemandu di event Sonntagsspaziergang: Bäume bestimmen berbicara pada kami, "der wald ist die Deutsche seele" (hutan adalah jiwanya orang Jerman). Hutan adalah jiwa yang diidentifikasi Jerman melekat pada emosionalitas, terpatri dalam pikiran dan ditegaskan sebagai identitas. Semata-mata ia ingin memberikan pandangan yang menggeneralisir bahwa hutan Jerman dalam heimat yang mereka miliki adalah sumber semangat berkebudayaan yang 
diartikulasikan pada senarai tindakan-tindakan baru—terlepas dari diskusi dan perdebatan tentang heimat itu sendiri.

Citra jiwa Jerman melalui hutan dalam perjalanannya telah direproduksi dari abad ke abad. Meski tidak semua menyatakan secara eksplisit jiwa yang dimaksud, tetapi polanya itu terbentuk dalam pandangan-pandangan individu dan kolektif. Apabila mengingat cerita Stephen Spender, seorang jurnalis Britania, tutupan hijau yang ia sambangi di tahun 1946an itu sangat merepresentasikan apa yang disebut Jerman, "The German landscape seems very German to me” (Spender dalam Lekan 2004). Akan tetapi, eksplorasi terkait jiwa Jerman, hutan dan identitas sendiri terus menyisakan pertanyaan bagi saya dan barangkali kajian ilmu antropologis, bagaimana sejatinya identitas itu terbentuk dan disadari secara kolektif melalui heimat?

Armin Nassehi, sosiolog Jerman keturunan Iran, meragukan heimat sebagai patok utama dalam meneguhkan identitas (Krämer 2018). Meski dulu heimat ini dipakai partai politik untuk menetapkan latar belakang ideologinya, agaknya kini heimat juga masih menjadi alat dalam politik identitas. Nassehi menyebut eksklusivitas dan juga superior Jerman hanya akan menambahkan rasa tekanan primordialis ini semakin kuat. Seperti Minister of Interior, Construction and Heimat, Horst Seehofer, yang kontroversial menyebut, "Islam doesn't belong to Germany". Oleh karena itu, saya sepakat dengan definisi heimat yang disuguhkan Nassehi bahwasanya heimat bukan hanya jawaban tentang di mana manusia (Jerman) itu berada tanpa harus membenarkan diri mereka sendiri, tetapi juga berarti bahwa orang lain "others" mengakui hak Jerman atas itu.

Dalam diskursus ekologi politik, konsep heimat adalah konsekuensi dari meledaknya modernisasi dan mobilitas yang serba cepat, yang diartikan seperti motivasi baru dalam pergerakan lingkungan dan dimaknai sebagai bentuk kecintaan terhadap tanah air dan lingkungannya. Namun dalam praktik sehari-hari, kemunculan pandangan-pandangan ini acapkali mengikhtisarkan persepsi individu yang "cinta" akan lingkungan, dan bahkan beberapa darinya tidak berdasar alasan ekologis. Tsing (2005) kerap menyebut fenomena seperti ini sebagai "nature-lover" - segerombol pecinta lingkungan yang menyajikan letak kecintaannya pada lingkungan atas keelokan lanskapnya. Dalam karya etnografinya, praktik ini disebut sebagai "nature loving" yang mengeksplorasi kecintaan orang Dunia Selatan pada lingkungan untuk mendapatkan energi. Melihat ini, apakah dapat dikatakan alasan-alasan subjektif individu itu bagian dari heimat, sedangkan narasi yang terbangun kadang mengikhtisarkan "nature-lover" (kecintaan lingkungan), yang barangkali kelekatan dengan tanah air (Jerman), itu sendiri masih dipertanyakan? Jawabannya dinamis karena melekatnya Jerman dalam hutan dan kehadiran konstruksi jiwa Jerman itu sendiri memiliki sejarah panjang dan tak ayal dikontestasikan.

Untuk mengkritisi dan menapaki kembali jejak heimat, saya ingin mendiskusikan soal konsep The Archeology of Knowledge oleh Foucault (2002) - yang selanjutnya disebut Arkeologi Pengetahuan-dalam menjawab persoalan ini, Foucault dalam Umanailo (2019) mendefinisikan Arkeologi Pengetahuan sebagai upaya mengeksplorasi sejumlah kondisi (fakta dan realita) historis yang dikombinasikan untuk membentuk dan mendefinisikan suatu bidang pengetahuan yang terpisah agar terbentuknya seperangkat konsep tertentu. Arkeologi Pengetahuan juga merupakan penjelajahan dan upaya menguak akan wacana dan nilai suatu hal. Artinya, pencarian jejak arkeologis suatu pengetahuan (knowledge) merunut pada diskursus (discourse) yang bersejarah dari gagasan, atau pemikiran, atau 
ilmu, atau pengetahuan (Fahroji 2020).

Lahirnya pengetahuan tentang hutan dan lingkungan serta gagasan mengenai heimat (tanah air) Jerman merupakan sebuah artefak arkeologis yang dalam bentuk tradisionalnya digunakan untuk menghormati tradisi atau monumen masa lampau, yang memiliki kisah, cerita, dan ritus kebudayaan di ruang dan waktu tertentu (Foucault 2002, 5). Maka, artefak (perawatan pengetahuan) hutan dari memori orang Jerman Selatan sebagai 'monumen' yang memiliki sederet arsip (archive) yang dikumpulkan dari periode tertentu adalah produk dari arkeologi pengetahuan.

Lantas, saya sepakat dengan Foucault bahwa arsip (archive) bukanlah serangkaian hal ( $a$ set of things) atau serangkaian pernyataan (a set of statements), melainkan serangkaian hubungan (a set of relation) - yang mana serangkaian hubungan ini memungkinkan kondisi itu terus ada. Pada konteks heimat, serangkaian hubungan ( a set of relation) itu tertulis pada jejak hubungan manusia dengan hutannya, mulai dari adanya praktik tradisional dan kecintaan terhadap lingkungan orang Jerman Selatan di abad ke-16 hingga kini, atau juga bisa dilihat pada praktik perawatan hutan di Waldhaus sebagaimana riset ini dipadukan. Namun secara kronologis, saya ingin mengatakan bahwa narasi heimat ini dikontestasikan dan dipalsukan pada rekayasa kekuasaan; yang dinyatakan dan mengalami diskontinuitas.

Jelas pada masa Nazi berkuasa di Jerman, atau bahkan masa kekaisaran Prusia di Jerman (abad ke-17), pergeseran makna heimat menjadi ideologi jahat Darah dan Tanah seakan membuat citra bahwa tanah air Jerman abadi dan unggul di atas segalanya (Wilson 2012). Hal ini menyatakan arsip baru bahwa heimat secara politis adalah bentuk nasionalisme baru. Tentu saya melihat artefak ini menjadi suatu pengetahuan (knowledge) yang di reproduksi saat itu untuk menciptakan diskursus baru dan dinaturalisasi sebagai genealogi kekuasaan. Dalam hal ini, kekuasaan membentuk domain-domain objek, di mana masing-masing domain bisa mengafirmasi atau menyanggah kebenaran atau kekeliruan proposisi-proposisi sebelumnya (Umanailo 2019, 6). Akibatnya, reproduksi kekuasaan ini dianulir dan dibatasi dalam pernyataan-pernyataan saat itu dan berpengaruh pada perubahan citra heimat. Adanya diskontinuitas pengetahuan (savoir) menjadi ambang (threshold) — di mana pada satu titik waktu tepatnya dalam hal ini pasca bubarnya Nazikonsep heimat mengalami ambang (atau tak berposisi) pada pernyataan, objek, konsep, strategi, atau posisi subjek sebelumnya.

Dengan demikian, proposisi kekuasaan dalam pergumulan konsep heimat menjembatani pada satu konsep apa yang Foucault sebut sebagai "unsaid" atau lebih lekat disebut "tabu". Oleh karena heimat itu sudah dimanipulasi oleh Hitler dan jika dibicarakan maka akan mengenang kejahatan, rasisme, budaya patriarkal, dan nasionalisme ekstrem kanan, konsep ini menjadi tidak dapat diucapkan. Namun dalam the archeology of knowledge bayangan mengenai yang "tabu" ini memiliki artefak dan arsip yang dinyatakan pada masanya dan itu disebut sebagai monumen. Dalam hal ini, bentuk-bentuk tindakan tradisional perawatan hutan dan kecintaan terhadap lingkungan dari statements dan gagasan hutan memberi energi menjadi monumen atau tiang awal di mana heimat dikonsepkan. Konsep Heimat dalam hutan menjadi domain baru yang acapkali nilai-nilainya masih tumbuh saat ini namun tidak disadari secara penuh oleh orang Freiburg. Saya menegaskan bahwa arkeologi pengetahuan dalam bagian ini ingin menyempurnakan kritik pada heimat yang masih "tabu" dibicarakan, namun rupanya nilai-nilai tradisional yang mengakar tidak luntur melainkan dipraktikkan dengan cara yang berbeda. Bagaimanapun, refleksi atas 
heimat dan kehutanan Jerman dalam studi antropologi menjadi suatu kebaruan pandang dalam menelaah representasi kebangsaan, identitas dan dinamika lingkungan pada karyakarya tulis yang sifatnya etnografis.

\section{Kesimpulan}

Hutan Jerman yang sepanjang sejarahnya dikontestasikan pada pembentukan simbol nasional, kepentingan popularitas hingga munculnya gerakan kesadaran lingkungan, rupanya memiliki relasi kultural yang sifatnya sehari-hari dan dirasakan secara personal. Studi mengenai hutan-hutan Jerman dalam praktik kebudayaan seolah mengikhtisarkan satu hal, yakni kehidupan alam yang abadi dengan perasaan belonging yang dapat manusia rasakan, alih-alih perasaan kelekatan atas bangsanya. Menurut William (1996), kelekatan itu tidak hanya mengejawantahkan pengetahuan, tetapi juga spirit dalam jiwa. Oleh sebab itu, kelekatan ini tak lain adalah hasil dari refleksi masyarakat Jerman Selatan terhadap dikotomi lingkungan yang mewujud pada realitas-realitas baru di antara masyarakatnya.

Relasi manusia-hutan akhirnya tidak hanya mewujud secara fisik, tetapi ia lebih daripada itu. Konstruksi hutan dari masa ke masa yang diatur guna aksesibel dan bernilai humanis bagi semua orang adalah definisi rumah yang embedded (melekat) pada pikiran, emosionalitas dan aktivitas sehari-hari. Namun, tentunya bicara heimat dalam konteks kehutanan hanyalah menjawab salah satu perspektif relasi manusia-hutan terhadap identitas kebudayaan mereka. Heimat masih dilihat dan dapat dikontekstualisasikan juga dengan diskursus lain, seperti politik, pembangunan ekonomi, infrastruktur dan aspek lainnya. Hutan, seperti penelitian yang sudah saya jalani ini, merupakan symptom klasik dalam melihat identitas Jerman. Menyadari akan keklasikan studi ini, satu hal yang bisa dipelajari adalah hutan di Jerman Selatan sejatinya (dan akan) terus menjadi "hutan biologis". Ia hanya berubah peran pada praktiknya, dan beralih rangka dalam sebuah pandangan yang diwacanakan. Kalau kata Wilson Jeffrey, hutan Jerman itu akan selalu dimaknai sepanjang sejarah hubungan manusia dan alam (hutan) itu ada.

Meskipun demikian, saya dapat mengatakan kalau penelitian ini tidak hanya deskriptif dan interpretif melihat hutan sebagai metafora bagi orang Jerman Selatan. Lebih daripada itu, studi ini tak lain merupakan studi antropologi yang kritis dan politis, yang melihat hutan Jerman bukan secara teknis dan literal: bahwa hutan di Jerman itu tidak muncul tiba-tiba begitu saja. Itu muncul dari konsep tradisional orang Jerman Selatan tentang hutan sebagai bayangan tanah air, di mana akarnya telah menjadi semangat kebudayaan orang Freiburg dalam mencintai dan merawat lingkungannya.

Bagaimanapun, studi singkat mengenai makna hutan ini telah membuka jalan studi lanjutan terkait proyeksi kognitif bagi masyarakat Freiburg secara khusus, dan Jerman secara umum, dalam membangun kesadaran lingkungan (environmental consciousness) dan pemaknaan simbolik terhadap hutan-yang terpatri dalam perasaan kelekatan (sense of belonging). Hutan Jerman, secara final dalam pandangan saya, adalah ruang kehidupan di mana letak kesadaran, logika praktik kehutanan yang humanis, dan perasaan kelekatan manusia terhubung satu sama lain untuk mengabadikan identitas, baik secara personal (afeksi) maupun kolektif (nasional). [] 


\section{Referensi}

Agrawal, A. 2005. Environmentality: Technologies of Government and the Making of Subjects. United States: Duke University Press.

Ahimsa-Putra, H.S. 2013. "Budaya Bangsa, Jati Diri dan Integrasi Nasional: Sebuah Teori." Jurnal Jejak Nusantara. No. 1 ed.1 hlm 6-19.

Anderson, B. 1991. Imagined Communities: Reflections on the Origin and Spread of Nationalism. Edisi Kedua. London: Verso, 1991.

Askins, R.A. 2014. Saving the World's Deciduous Forests. Ecological Perspectives from East Asia North America, and Europe. New Haven: Yale University Press.

Birkenstock, Günter. 2014. "Mitos Hutan di Jerman”. DW. Diakses pada Jumat, 17 April 2020 pukul 05.20. https://www.dw.com/id/mitos-hutan-di-jerman/a-14833142.

Blackbourn, D. 2013. "The Culture and Politics of Energy in Germany: A Historical Perspective", dalam RCC Perspectives, No. 4, The Culture and Politics of Energy in Germany: A Historical Perspective, hal. 1-31.

Brandl, H. 2006. "Farms in the black forest of Baden-Württemberg: A historical review." Small-scale Forestry, Vol. 5, 145-159.

Borchmeyer, Dieter. 2019. "Into the Woods: A very special relationship, Germans and their forest.” LIFE, April 2019, diakses pada Minggu, 19 April 2020 pukul 16. 53. http:// www.german-times.com/a-very-special-relationship-germans-and-their-forest/.

Cassirer, E. 1945. An Essay on Man. Yale: Yale University Press.

Cronjäger, L. 2021. "The Curated Forest: Seeing Aesthetically and Scientifically”. Makalah Seminar Medienwissenschaft, Basel: Universität Basel.

DW Euromaxx. 2020. "Love, Dating And Sex in Germany”. DW Euromaxx Youtube, https:// www.youtube.com/watch?v=la_RQGWqOko,

Fahroji, F.R. 2020. Heimat dalam Hutan Jerman yang Diceriterakan: Kelekatan dan Subjektivitas Lingkungan dalam Praktik Penggunaan Hutan di Freiburg, Jerman. Skripsi. Yogyakarta: Universitas Gadjah Mada.

Foucault, M. 2002. The Archeology of Knowledge. Britain: Routledge.

Harrison, R. 1992. Forest: The Shadow of Civilization. Chicago: University of Chicago Press.

Imort, M. 2005. "Eternal Forest - Eternal Volk': Rhetoric and Reality of National Socialist Forest Policy" dalam How Green Were the Nazis? Nature, Environment and Heimat in the Third Reich, Franz-Josef Brüggemeier, Mark Cioc, dan Thomas Zeller (eds), 43 - 72. Athens, $\mathrm{OH}$ : Ohio University Press.

Imort, M. 2005. "A Sylvan People: Wilhemine Forestry and the Forest as a symbol of Germandom" dalam Germany's Nature: Cultural Landscapes and Environmental History, Thomas Lekan and Thomas Zeller (eds), 55 - 80. New Brunswick, NJ: Rutgers University Press.

Jäger, J. 2018. "Heimat (English version)". Docupedia Zeitgeschichte, http://docupedia.de/ zg/Jaeger_Heimat_v1_en_2018

Krämer, K. "Patriotic term 'Heimat' driving new German 'identity politics”'. DW 29 March 2018, https://www.dw.com/en/patriotic-term-heimat-driving-new-german-identitypolitics/a-43150157?maca=en-GK-RSS-Alumniportal-VT-CP-Culture-26077-htmlcopypaste .

Lee, R. G. dan Wilke, Sabina. 2005. "Forest as Volk: Ewiger Wald and the Religion of Nature 
in the Third Reich". Journal of Social and Ecological Boundaries, 21-46.

Lekan, T. 2004. Imagining the Nation in Nature: Landscape Preservation and German Identity, 1895 - 1945. Cambridge: Harvard University Press.

Lekan, T. dan Zeller, T. 2005. Germany's Nature: Cultural Landscapes and Environmental History. United States of America: Rutgers University Press.

Linke, U. 1990. "Folklore, Anthropology, and the Government of Social Life". Comparative Study of Society and History 32, No. 1, 117-48.

Moore, J.D. 2012. "Marvin Harris: Cultural Materialism" dalam Vision of Culture. New York: Altamira Press.

O'Brien, E.A. 2005. "Publics and Woodlands in England: well-being, local identity, social learning, conflict and management". Forestry. Vol. 78, No. 4, doi:10.1093/forestry/ cpi042.

Radkau, J. 1996. "Wood and Forestry in German History: In Quest of an Environmental Approach" dalam Environment and History, Vol. 2, No. 1, hal. 63-76.

Ratter, B.M.W dan Gee, K. 2012. "Heimat - A German concept of regional perception and identity as a basis for coastal management in the Wadden Sea." Elsevier: Ocean \& Coastal Management, Vol. 68, hal. 127-137.

Smith, A.D. 1986. The Ethnic Origins of Nations. Cambridge, MA: Blackwell.

Svasek, M. 2002. "Narratives of "Home" and "Homeland": The Symbolic Construction and Appropriation of the Sudeten German Heimat." Identities, Vol. 9, No. 4, hal. 495-518, DOI: $10.1080 / 10702890214871$.

Tange, J. 2018. No Place Like Home, But What Does Home Look Like? An Analysis Of The Influence Of The German Discourse Of Place, Belonging, And Identity In West And East German Heimat Films. Tesis. Utrecht: University Utrecht.

Thomasius, H. 1994. "The Influence of Mining on Woods and Forestry in the Saxon Erzgebirge up to the Beginning of the $19^{\text {th }}$ Century." Springer: GeoJournal, Vol. 32, No. 2, hal. 103-125.

Tsing, A. 2005. Frictions: An Ethnography of Global Connection. United Kingdom: Princeton University Press.

Umanailo, MCB. 2019. “Pemikiran Michel Foucault.” https://www.researchgate.net/ publication/336764837.

Warde, P. 2006. "Fear of Wood Shortage and the Reality of the Woodland in Europe, c. 1450-1850." History Workshop Journal, No. 62, pp. 28-57.

Wilson, J.K. 2012. The German Forest: Nature, Identity, and the Contestation of a National Symbol, 1871 - 1914. Toronto: Toronto University Press. 